\title{
Functional probiotic yoghurt production with black mulberry (Morus nigra L.) juice concentrate fortification
}

\author{
Kavas Nazan ${ }^{1, *}$ and Kavas Gökhan ${ }^{2}$ \\ ${ }^{1}$ Dairy Products Program, Ege Vocational Training School, Ege University, 35100 İmir, Turkey. \\ 2 Department of Dairy Technology, Faculty of Agriculture, Ege University, 35100 İmir, Turkey.
}

Publication history: Received on 18 October 2018; revised on 31 October 2018; accepted on 05 November 2018

Article DOI: https://doi.org/10.30574/gscbps.2018.5.2.0120

\begin{abstract}
In this study, probiotic yoghurts (PYX and $\mathrm{PY}_{\mathrm{Y}}$ ) were produced with cow's milk with $13 \%$ dry matter standardized concentration by $3 \%$ skim milk powder addition and Black Mulberry (Morus nigra L.) juice concentrate (BMJC) fortification at different ratios $(1 \% \mathrm{v} / \mathrm{v}$ and $2 \% \mathrm{v} / \mathrm{v})$ One sample was produced as plain yoghurt (PY). The samples were stored at $+4^{\circ} \mathrm{C} \pm 1$ for 14 days. Microbiological, sensory properties as well were analyzed at the $1^{\text {st }}, 5^{\text {th }}, 10^{\text {th }}$ and the $14^{\text {th }}$ days of the storage. The relation between BMJC fortification and viability and numerical increase of probiotics were significant $(\mathrm{p}<0.05)$. The increase in BMJC level improved the mentioned parameters. In the study, the relation between BMJC fortifications and the microbiological of yoghurts were significant. Conclusively, $1 \%$ (w/v) and $2 \%$ (w/v) BJC fortification improved the functional properties of yoghurt samples.
\end{abstract}

Keywords: Black Mulberry; Morus nigra; Probiotic yoghurts

\section{Introduction}

Yogurt, the best carrier of probiotics, traditionally is manufactured using Streptococcus thermophilus and Lactobacillus delbrueckii ssp. bulgaricus (L. bulgaricus) as starter cultures [1]. Probiotics are referred to as 'live microorganisms, which when administered in adequate amounts confer a health benefit on the host [2]. The majority of commercial probiotics are Lactobacillus and bifidobacteria species used in products such as yogurt, milk powder and frozen desserts [3-4]. They produce short-chain fatty acids and improve the intestinal microbial balance, resulting in the inhibition of bacterial pathogens, reduction of colon cancer risk, improving the immune system and lowering serum cholesterol levels [4]. Probiotic dairy product should contain at least $10^{6}-10^{7} \mathrm{cfu} / \mathrm{mL}$ of viable probiotic bacteria at the time of consumption [5]. However, in fermented products various probiotic lactobacilli and bifidobacteria show the decline in their viability during storage [6]. Today there has been increase in trend to fortify the dairy product with fruits and fruit parts to improve their nutritional value and the taste.

Foods based on fruit and vegetables, such as fruit and vegetable juices, represent a new potential carrier and source of probiotic microorganisms [7-8]. Raw and fermented vegetables also represent an excellent vehicle for probiotics due to their natural structure that allows the easy availability of useful nutrients for microbial growth [8-9]. Some operations such as peeling and cutting performed on minimally processed products can favor the availability of nutrients, such as sugars, vitamins, and minerals needed for probiotic growth [9]. Moreover, most fruits and vegetables contain prebiotic ingredients that promote the growth of beneficial microorganisms. But not all probiotic strains added to fruits and vegetables give good results in terms of survival. In fact, numerous factors influence microbial growth, such as salt, acidity, and $\mathrm{pH}$. The viability of probiotic microorganisms in food matrices depends on several factors, such as storage temperature, oxygen levels, $\mathrm{pH}$, and the presence of competitor microorganisms, which must all be carefully evaluated

\footnotetext{
${ }^{*}$ Corresponding author

E-mail address: nazan.kavas@ege.edu.tr
} 
before they are added to foods [10]. Also in fruit and vegetable juices, the tolerance to acidity is particularly important. These juices are already naturally acidic; the fermentation process increases the acidity. Nevertheless, results the presence of proteins, minerals, fiber, and other nutrients promotes the survival of microorganisms, introducing a new concept of symbiotic food [11]. Therefore, vegetable and fruit juices (like carrot juice, melon juice) have been tested to assess their suitability to be used as a carrier of probiotics. In the research results carrot and melon juices is rich in sucrose, glucose, and fructose, possible sources of carbon for bifidobacteria. However, in this case, only glucose and sucrose have been used by microorganisms [12-13].

The fermentation of fruit-based probiotic products requires proper selection of microbial strains, the type of fruit juice with appropriate physicochemical properties and cultivation conditions for the optimal growth. The optimum cultivation factors include the water activity, processing and storage temperature, oxygen content and mechanical stress [14]. Results revealed that fruit juices might be suitable to be a medium to cultivate probiotic lactic acid bacteria. This is mainly due to the favorable acidic $\mathrm{pH}$ of fruit juices, typically between 2.5 and 3.7 for the growth of probiotics [15]. Possibly, the low pH and high acidity of fruit juices appear to be good for the survival of probiotic strains, even though they are not growing in the juice. The strains are able to resist the acidic condition after transported from stomach to intestine. Their impressive acidic tolerance makes them eligible to be developed into functional supplements in fruit juices [15]. Fruit juices are also good sources of saccharides for the growth of probiotic bacteria, and rich in phenolic compounds for the inhibition of pathogenic microorganisms $[3,16]$. Dairy-based probiotic foods and drinks are one of the industrial scaled production of probiotic products in the market. Several researchers explained about the physicochemical composition of milk which is rich in protein and substantial lipid amount could be a protective matrix for probiotics [17].

Mulberry (Morus species) juice obtained from black mulberry (BM, (Morus nigra L) contains rich source of bioactive compounds including phenolic substances like flavonoids and anthocyanins with high antioxidant activity [18]. Flavonoids have long been recognized to possess anti-inflamma-tory, antioxidant, antiallergic, hepatoprotective, antithrombotic, antiviral and anticarcinogenic activities. This phytonutrient protects our body from the harmful oxidation of free radicals. Specifically, mulberry contains cyaniding 3-glucoside, which epidemiological studies confirm lowers the risk of many degenerative diseases such as chronic arthritis and antherosclerosis. Cyaniding 3-glucoside protects the body against cardiovascular disease and diabetes. Mulberry along with improving blood circulation can help people who suffer from heart palpitations. Fresh mulberry fruits are rich in protein (2.5\%), total fat (2\%), vitamins (especially vitamin C level 61 \%, vitamin K level 6.5 \%), carbohydrates (7.8-9 \%) and mineral, such as Zn, Mn, Fe, Ca that are indispensable for the human body. In addition, mulberry fruits are also rich in pectin and fibrin. Ascorbic acid content is as high as $20 \mathrm{mg} / 100 \mathrm{~g}$ in fresh fruit [19]. Mulberry fruits are an excellent source of the antioxidants resveratrol, zeaxanthin, litein and to a lesser extent the alpha and beta carotene. Isolation of lactic acid bacteria (LAB) from fruits and vegetables have frequently been reported [20]. Mulberry (Morus spp.) is an important fruit in Turkey, with a production rate of 74,600 tonnes in 2013. Approximately, $95 \%$ of the mulberry trees grown in Turkey are Morus alba (white mulberry), while the remaining are Morus rubra (red mulberry) (3\%) and M. nigra (black mulberry) ( $2 \%$ ) [21]. Black mulberry juice is a potential source of anthocyanins that have high antioxidant activity and thus many health benefits [22,23]. However, black mulberry (BM) phytochemicals, mainly anthocyanins, are labile to heat treatment and storage depending on temperature, light and $\mathrm{pH}$ [24]. Black mulberry juice is well-known not only for its nutritional quality and distinctive flavor, but also as a good source of several bioactive phytonutrients [25] In general, the fruits of Mulberry were evaluated as a rich source of carbohydrates and sugars (respectively sucrose, glucose, fructose) [26].

In this study, probiotic yoghurts were produced with cow's milk with $13 \%$ dry matter standardized concentration by 3 $\%$ skimmed milk powder addition and black mulberry juice concentrate (BMJC) fortification at different ratios ( $1 \% \mathrm{v} / \mathrm{v}$ and $2 \% \mathrm{v} / \mathrm{v}$ ). Yoghurt samples were stored for 14 days at $+4{ }^{\circ} \mathrm{C} \pm 1$, and microbiological analysis were conducted on the $1^{\text {st }}, 5^{\text {th }}, 10^{\text {th }}$ and $14^{\text {th }}$ days of the storage.

\section{Material and methods}

\subsection{Material}

Raw cow's milk (CoM) used in the study was obtained from Ege University Department of Animal Science, black mulberry (Morus nigra L.) used in the production of black mulberry juice concentrate (BMJC) was obtained from a local producer in, Aydın (Turkey), skim milk powder (SMP) was obtained from Pınar Sut Inc. (Turkey), probiotic yoghurt culture YO-MIX 205 (Str. thermophilus + Lb. bulgaricus, + Lb.acidophilus) (Danisco-FRANCE) and freeze-dried yoghurt culture BIFI (Bifidobacterium ssp.) was obtained from CSL laboratories (Strade per Merlino, 3- 26839, Italy). Probiotic yoghurt production was conducted in Ege University Dairy Technology Pilot Plants. 


\subsection{Black mulberry juice concentrate (BMJC) production}

In BMJ production, black mulberry was washed with water, separated to their pieces and pressed in press (BucherGuyer, Niederweningen, Switzerland) under 0.3-0.5 bar for 5 second and the juice was clarified. In the clarification of BMJ, $0.5 \mathrm{~g} / \mathrm{L}$ (Sigma-Aldrich) gelatin which was determined as a result of preliminary trials was added to the black mulberry juice and waited for 15 minutes. Then $0.3 \mathrm{~g} / \mathrm{L}$ bentonite was added (Sigma-Aldrich) and kept at water bath at $50^{\circ} \mathrm{C}$ for 30 minutes. Clarification process was applied to the black mulberry juice and cooled to room temperature. Black mulberry juice was filtered through a filtration system consisting of cheesecloth and filter paper and separated from the sediments. Then it was concentrated (BMJC) to $62^{\circ}$ Brix value in a laboratory type rotary evaporator (SCILOGEX RE 100 -Pro/20 - $280 \mathrm{rpm}$ ) at $85 \pm 1{ }^{\circ} \mathrm{C}$ and stored at $4{ }^{\circ} \mathrm{C} \pm 1$. Total dry matter, water soluble dry matter $\left({ }^{\circ}\right.$ Brix), pH and titratable acidity of BMJ were determined on the 0 th day of the storage.

\subsection{Probiotic yoghurt (PY) production}

In this study, probiotic yoghurts (PYX and $\mathrm{PY}_{\mathrm{Y}}$ ) were produced with cow's milk with 13\% dry matter standardized concentration by $3 \%$ skimmed milk powder addition and black mulberry (Morus nigra L.) juice concentrate (BMJC) fortification at different ratios $(1 \% \mathrm{v} / \mathrm{v}$ and $2 \% \mathrm{v} / \mathrm{v})$ and $6 \%$ starter culture (Str. thermophilus + Lb. bulgaricus + Lb. acidophilus and Bifidobacterium ssp.) mixture (1:1). Cow's milk was divided into 3 batches in yoghurt production. BMJC was added before pasteurization in order to maintain the degradation of anthocyanins [27] and make a lesser effect on the color properties of yoghurt samples. Accordingly, the $1^{\text {st }}$ batch was the plain batch while the 2 nd batch was fortified with only $1 \%(\mathrm{w} / \mathrm{v})$ BMJC $(\mathrm{X})$ and the $3^{\text {rd }}$ batch was fortified with $2 \%(\mathrm{w} / \mathrm{v})$ BMJC (Y). The batches were then homogenized with Ultra Turrax Blender (at $1200 \mathrm{rpm}$ for 40 seconds) (IKA, Merc, Germany) and pasteurized at $85{ }^{\circ} \mathrm{C}$ for 20 minutes. Then the samples were cooled to $42-43{ }^{\circ} \mathrm{C}$ and inoculated with $6 \%(\mathrm{v} / \mathrm{v})$ starter culture. The samples were distributing to plastic cups (200 g) and left to incubation. The incubation was ended at $4.60 \mathrm{pH}$ ( $4.5 \mathrm{hours})$ and PY, PYX and PYy probiotic yoghurt samples were obtained. Samples were stored for 14 days at $4{ }^{\circ} \mathrm{C} \pm 1$, and microbiological analysis were conducted on the $1^{\text {st }}, 5^{\text {th }}, 10^{\text {th }}$ and $14^{\text {th }}$ days of the storage.

\subsection{Microbiological analysis}

Starter culture counts of the yoghurt samples were performed according to International Dairy Federation standard method [28-29]. L. acidophilus and Bifidobacterium spp. Counts were determined according to International Dairy Federation standard methods [30-31].

\subsection{Statistical analysis}

Samples were examined with 3 parallels and 2 repetitions. SPPS version 15 (IBM SPSS Statistics) statistical analysis software was used for analyses. Significance according to analysis of variance (ANOVA) was tested according to the Duncan multiple comparison test at $\mathrm{p}<0.05$ level.

\section{Results and discussion}

In the study, in CoM, dry matter was determined $11.23 \%$, fat $2.87 \%$, protein $3.01 \%$, lactose $2.85 \%$, ash $1.49 \%$, lactic acid $0.128 \%$, pH 6.50 , and viscosity was $2.72 \mathrm{cp}\left(20^{\circ} \mathrm{C}\right)$. Total dry matter content of BMJ at the 0 th day was determined as $15.10 \%$ while water soluble dry matter was $13.19^{\circ} \mathrm{Brix}, \mathrm{pH}$ was 4.02 , titratable acidity was $1.328 \%$.

\subsection{Microbiological properties}

Changes in L. bulgaricus, S. thermophilus, L. acidophilus and Bifidobacterium spp. levels in PY samples are given in Figure 1. In PY samples, development and viability of starter cultures improved as the BMJC levels increased. Indeed, probiotic content in PYY during storage was higher compared to that in PYx. The relation between fruit concentrate level and the probiotic levels was significant $(\mathrm{p}<0.05)$. This also had a positive effect on the development and viability of probiotics. It was reported that serum separation decreased as the fiber ratio in yoghurt production increased [32]. It was also reported that low serum separation helped the preservation of the symbiotic relationship between the starter cultures and the viability [4]. In the study, the samples with the highest probiotic contents were sorted as PYY, PYX and PY. Our study results were compatible with the studies reporting that starter cultures show a better development in the presence of some sugars (such as glucose, maltose) [33], and that the relation between this development and the fruit concentrate levels was significant [34-35]. It was reported that black mulberry juice contains high levels of sukroz and glucose and lower levels of fructose [26]. However, Sanchez et al. [36] reported that the predominant sugar was fructose $(\sim 61 \%)$ followed by glucose ( $39 \%)$, while sucrose was presented only at trace level in mulberry fruits sampled from Spain and they also found big genotypic differences among clones for different sugars. Ozgen et al. [23] declared that fructose and glucose contents of 14 black and red mulberry genotypes ranged from 4.86 to $6.41 \mathrm{~g} / 100 \mathrm{~mL}$, and 5.50 to 
$7.12 \mathrm{~g} / 100 \mathrm{~mL}$, respectively. The present genotypes illustrated wide variability for the sugars, which may be ascribed to genetic factors, cultural applications, and ecological conditions (light, temperature, and humidity etc.) as also referred in the previous studies [37].

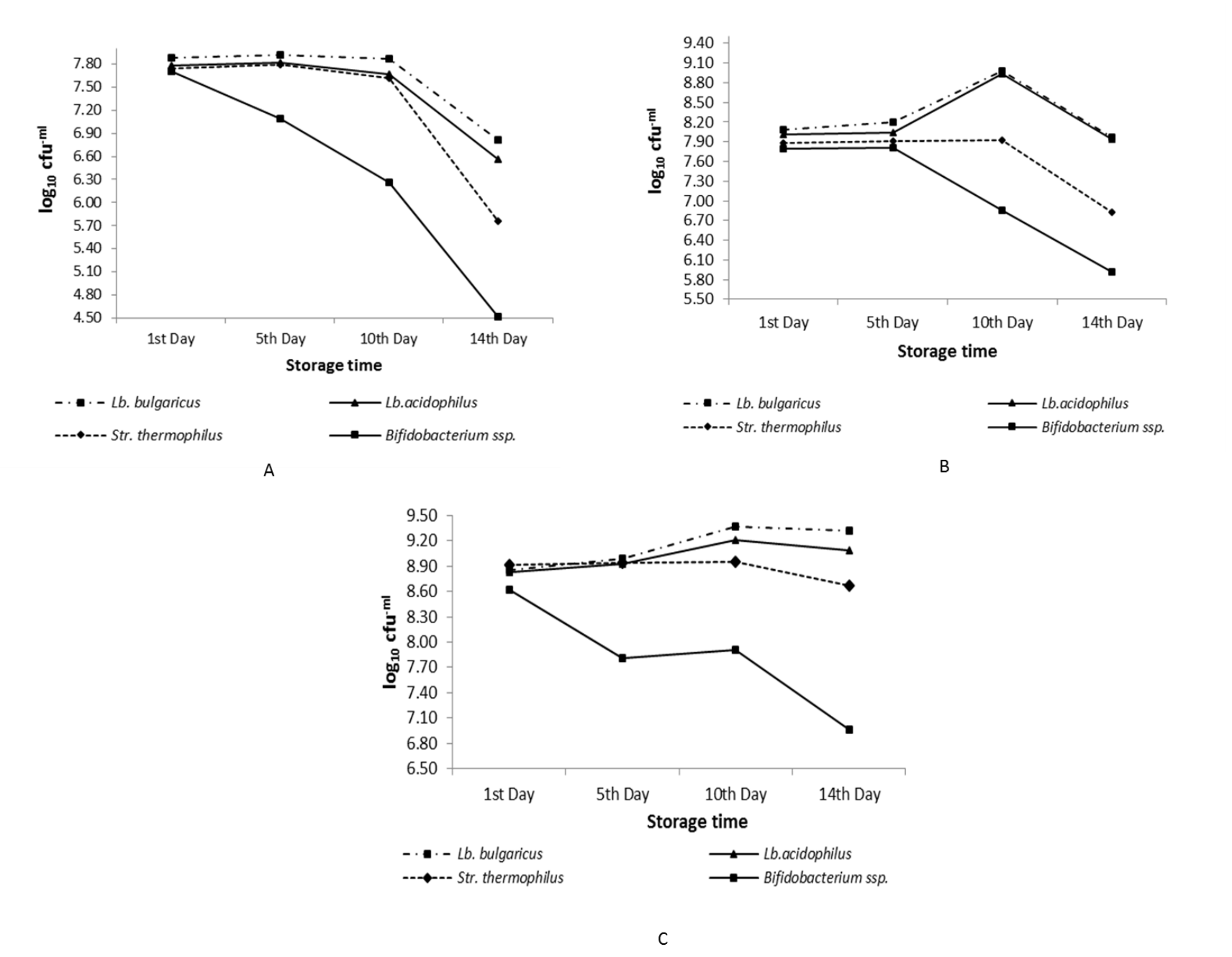

Figure 1 L. bulgaricus, L. acidophilus, Bifidobacterium spp. and S. thermophilus counts in PY (A); PYX (B) and PYY (C) samples during storage

In general, probiotics in PY, PYY and PYX increased from the $1^{\text {st }}$ day of the storage. The highest increase in PYY and PYX was determined at the $10^{\text {th }}$ day while it was determined at the $5^{\text {th }}$ day in PY. Bifidobacterium spp. level in PY decreased to $7.09 \log _{10} \mathrm{cfu} / \mathrm{ml}$ at the $5^{\text {th }}$ day. Probiotic levels decreased after the $10^{\text {th }}$ day in PYY and PYX and after the $5^{\text {th }}$ day in PY. The highest decrease was determined in PY, PYX and PYY samples, respectively. The increase in PYY was higher than that in $P_{X}$, whereas the decrease was lower. The increase in probiotics levels in PY was lower than those in PYY and PYx, however the decrease was higher. Probiotics with the highest viability were sorted as L. acidophilus and Bifidobacterium spp. Microorganism level at the $1^{\text {st }}$ day in PY was $7 \log _{10} \mathrm{cfu} / \mathrm{ml}$, while it was $8 \mathrm{Log} 10 \mathrm{cfu} / \mathrm{mlin}$ PYY. L. bulgaricus, L. acidophilus levels in PYX was $8 \log _{10} \mathrm{cfu} / \mathrm{ml}$, while $S$. thermophilus and Bifidobacterium spp. level was $7 \log _{10} \mathrm{cfu} / \mathrm{ml}$. The level of probiotics in PYx was higher compared to that of PY. Bifidobacterum spp. levels in the final products were low in PY (4.52 $\left.\log _{10} \mathrm{cfu} / \mathrm{ml}\right)$ and PYx $\left(5.26 \log _{10} \mathrm{cfu} / \mathrm{ml}\right)$.

\section{Conclusion}

In this study, $1 \%(\mathrm{w} / \mathrm{v})$ and $2 \%(\mathrm{w} / \mathrm{v})$ BMJC fortification used in the yoghurt production improved the textural, sensory and microbiological properties compared to those of PY. Higher levels of BMJC fortification improved these properties. The viability of probiotics in the final product increased with BMJC fortification. Conclusively, it was determined that probiotic yoghurt production with increased functionality is possible. 


\section{Compliance with ethical standards}

\section{Acknowledgments}

The authors is very grateful to the many thank's to managers of Ege Vocational Training School and Faculty of Agriculture, Ege University, 35100 İzmir /Turkey for providing the laboratory facilities during the study.

\section{Disclosure of conflict of interest}

The authors have not declared any conflict of interests.

\section{References}

[1] Lourens-Hattingh A and Viljoen BC. (2001). Yoghurt as probiotic carrier food. International Dairy Journal, 11, 117.

[2] FAO/WHO. (2001). Health and Nutritional Properties of Probiotics in Food including Powder Milk with Live Lactic Acid Bacteria. Report of a Joint FAO/WHO Expert Consultation on Evaluation of Health and Nutritional Properties of Probiotics in Food Including Powder Milk with Live Lactic Acid Bacteria. Cordoba, Argentina October, 1-4.

[3] Shah NP. (2007). Functional cultures and health benefits. International Dairy Journal, 17, 1262-1277

[4] Tamime AY and Robinson RK. (1985). Yoghurt: science and technology. Oxford, UK: Pergamon Press.

[5] Boylston TD, Vinderola CG, Ghoddusi HB and Reinheimer JA. (2004). Incorporation of Bifidobacteria into cheeses: challenges and rewards. International Dairy Journal, 14, 375-387.

[6] Paseephol T and Sherkat F. (2009). Probiotic stability of yoghurts containing Jerusalem artichoke inulins during refrigerated storage. Journal of Functional Foods, 1, 311-318.

[7] Peres CM, Peres C, Hernández-Mendoza A and Malcata F X. (2012). Review on fermented plant materials as carriers and sources of potentially probiotic lactic acid bacteria-With an emphasis on table olives. Trends in Food Science and Technology, 26(1), 31-42.

[8] Sheela T and Suganya R S. (2012). Studies on anti-diarrhoeal activity of symbiotic plums juice. International Journal of Scientific and Research Publications, 2(2), 1-5.

[9] Soccol CR, Vandenberghe LPS and Spier MR. (2010). The potential of probiotics. Food Technology Biotechnology, 48(4), 413-434.

[10] Gupta S and Abu-Ghannaman N. (2012). Probiotic fermentation of plant based products: Possibilities and opportunities. Critical Review in Food Science and Nutrition, 52(2), 183-199.

[11] Kalui MC, Mathara JM and Kutima PM. (2010). Probiotic potential of spontaneously fermented cereals based foods-A review. African Journal of Biotechnology, 9(17), 2490-2498.

[12] Fonteles TV, Costa MGM, Jesus ALT and De Rodrigues S. (2012). Optimization of the fermentation of cantaloupe juice by Lactobacillus casei NRRL B-442. Food and Bioprocess Technology, 5(7), 2819-2826.

[13] Kun S, Rezessy-Szabò JM, Nguyen QD and Goston-Hoschke A. (2008). Changes of microbial population and some components in carrot juice during fermentation with selected Bifidobacterium strains. Process Biochemistry, 43(8), 816-821.

[14] Vasudha S and Mishra HN. (2013). Nondairy probiotic beverages. International Food Research Journal, 20, 7-15.

[15] Sheehan VM, Ross P and Fitzgerald GF. (2007). Assessing the acid tolerance and the technological robustness of probiotic cultures for fortification in fruit juices. Innovation Food Science Emergency Technology, 8, 279-84.

[16] Kneifel W, Rajal A and Kulbe KD. (2000). In vitro behavior of probiotic bacteria in culture with carbohydrates of prebiotic importance. Microbial Ecology in Health and Disease, 12, 27-34.

[17] Nualkaekul S and Charalampopoulos D. (2011). Survival of Lactobacillus plantarum in model solutions and fruit juices. International Journal of Food Microbiology,146(2), 111-117. 
[18] Isabelle M, Lee BL, Ong CN, Liu X and Huang D. (2008). Peroxyl radical scavenging capacity, polyphenolics, and lipophilic antioxidant profiles of mulberry fruits cultivated in Southern China. Journal of Agricultural and Food Chemistry, 56(20), 9410-9416.

[19] Chu Y, Luo K, Chen S, Wang Y and Jang J. (2001). “The variety DL-number 1" In: Mulberry for animal feeding in China. Proceeding of a workshop, May 14-17, Hangzhou, P.R.China: 63-67.

[20] Minh NP and Dao DTA. (2013). Investigation of Saccharomyces Cerevisiae in Fermented Mulberry Juice. International Journal of Scientific \& Technology Research, 2, 11, 329-338.

[21] Ercisli S and Orhan E. (2007). Chemical composition of white (Morus alba), red (Morus rubra) and black (Morus nigra) mulberry fruits. Food Chemistry, 103(4), 1380-1384.

[22] Kong JM, Chia LS, Goh NK, Chia TF and Brouillard R. (2003). Analysis and biological activities of anthocyanins. Phytochemistry, 64(5), 923-933.

[23] Ozgen M, Serce S and Kaya C. (2009). Phytochemical and antioxidant properties of anthocyanin-rich Morus nigra and Morus rubra fruits. Scientia Horticulturae, 119, 275-279.

[24] Fazaeli M, Yousefi S and Emam-Djomeh Z. (2013). Investigation on the effects of microwave and conventional heating methods on the phytochemicals of pomegranate (Punica granatum L.) and black mulberry juices. Food Research International, 50(2), 568-573.

[25] Hojjatpanah G. Fazaeli M and Emam-Djomeh Z. (2011). Effects of heating method and conditions on the quality attributes of black mulberry (Morus nigra) juice concentrate. International Journal of Food Science \& Technology, 46(5), 956-962.

[26] Dimitrova MP, Petkova NT, Denev PP and Aleksieva IN. (2015). Carbohydrate Composition and Antioxidant Activity of Certain Morus Species. International Journal of Pharmacognosy and Phytochemical Research, 7(3), 621-627.

[27] Bonerz D, Wurth K, Dietrich H and Will F. (2007). Analytical characterization and the impact of ageing on anthocyanin composition and degradation in juices from five sour cherry cultivars. European Food Research and Technology, 224, 355-364.

[28] International Dairy Federation (IDF). (1997). Dairy starter cultures of Lactic Acid Bacteria (LAB) - standard of identity, standard no. 149A, IDF, Brussels, Belgium.

[29] International Dairy Federation (IDF). (2003). Yoghurt / enumeration of characteristic microorganisms - colony count technique at $37^{\circ} \mathrm{C}$, standard no. 117, IDF, Brussels, Belgium.

[30] International Dairy Federation (IDF). (2007). Selective enumeration of bifidobacteria in dairy products, development of a standard method. Bulletin of the International Dairy Federation 411/2007.

[31] ISO, 2006, ISO 20128:2006 (IDF 192: 2006) Milk product- enumeration of presumptive Lactobacillus acidophilus on a selective Medium-Colony-count technique at $37^{\circ} \mathrm{C}$.

[32] El-Nagar GF and Brennan CS. (2001). The influence of fiber addition on the texture and quality of stirred yoghurt. 8th Egyptian conference for dairy Science and Technology, 505-523.

[33] Shirai K, Guerrero I, Huerta S, Sauced G, Castillo A, Gonzalez RO and Hall GM. (2001). Effect of initial glucose concentration and inoculation level of lactic acid bacteria in shrimp waste ensilation. Enzyme and Microbial Technology, 28, 446-452.

[34] Champagne CP and Gardner NJ. (2008). Effect of storage in a fruit drink on subsequent survival of probiotic lactobacilli to gastrointestinal stresses. Food Research International, 4, 539-543.

[35] Hassanein AM, Eman TAY and El-Shazly HAM. (2014). Effect of concentrated pomegranate on probiotic yoghurt. World Applied Sciences Journal, 30(5), 567-574.

[36] Sanchez EM, Calin-Sanchez A, Carbonell-Barrachina AA, Melgarejo P, Hernandez F and Martinez-Nicolas JJ. (2014). Physicochemical characterization of eight Spanish mulberry clones: Processing and fresh market aptitudes. International Journal of Food Science and Technology, 49, 477-483.

[37] Gundogdu M, Muradoglu F, Sensoy RIG and Yılmaz, H. (2011). Determination of fruit chemical properties of Morus nigra L. Morus alba L. and Morus rubra L. by HPLC. Scientia Horticulturae, 132, 37-41. 
Kavas and Kavas / GSC Biological and Pharmaceutical Sciences 2018, 05(02), 096-102

\section{How to cite this article}

Kavas N and Kavas G. (2018). Functional probiotic yoghurt production with black mulberry (Morus nigra L.) juice concentrate fortification. GSC Biological and Pharmaceutical Sciences, 5(2), 96-102. 